\title{
Planning for sustainability at the destination level through limiting accessibility on the island of Spetses, Greece
}

\author{
A. Vassi \& G. Christodoulopoulou \\ National Technical University of Athens, Greece
}

\begin{abstract}
Spetses is the only Greek settlement which has a complete ban of traffic. Excessive use of motorcycles puts in danger not only the development of tourism on the island but also the island itself. This study aims at preserving the shape of the settlement, its natural and urban environment, improving the quality of life and promoting the development of tourism.

Keywords: sustainable tourism, areas of controlled accessibility, limiting accessibility.
\end{abstract}

\section{Introduction}

During the 1990s, the issue of sustainability was the subject of a discourse which resulted in the term "sustainable tourism". The Fifth Environmental Action Programme: Towards Sustainability, adopted by the European Commission in March 1992, was employed by the European Union to implement Agenda 21. Wilkinson [1] points out that the backbone of the Action programme was the need to integrate the needs of the environment into the development and implementation of other policies: agriculture; energy; industry; transport; tourism. Lane [2] describes the term of sustainable development as all the components chart a path for tourism development such that a destination area's environmental resource base (including natural, built, and cultural features) is protected for future development. Hunter [3] proposes 4 ways of interpreting sustainable tourism: 1. sustainable development through a "Tourism Imperative"; 2. sustainable development through "product-led tourism"; 3. sustainable development through "environment-led tourism"; 4. sustainable development through "“Neotenous Tourism". Some researchers, such as Butler [4], prefer the 
term 'sustainable development in tourism', involving the ideology of sustainability and which does not necessarily refer to a tourism-centric approach in development discussions and practices in which the evaluation is focused on the needs of the tourist industry [5]. Inskeep [6] points out that: "the sustainable development approach can be applied to any scale of tourism development from larger resorts to limited size special interest tourism". Leiper [7] highlights the fact that the inextricable relationship between transport and tourism is of fundamental importance in explaining the tourism system. Lumsdon and Page [8] and Page [9] realize that, within the academic discipline of transport, studies that focus on leisure or tourism settings are limited and yet leisure traffic can be significant. In the UK it accounts for $30 \%$ of all trips and $40 \%$ of all trip miles if visits to friends and relatives are included and it is dominant in the long-distance market, accounting for $58 \%$ of all UK trips over 50 miles (Department for Transport, 2005 [19]). This situation is not unique to the UK. German figures estimate that leisure trips account for $48 \%$ of all passenger kilometres [10]. Dickinson and Robbins [11] explore the contradiction in policy objectives as national governments are keen to promote tourism and leisure for their economic benefits (whilst at the same time there is an agenda to reduce congestion, greenhouse gas emissions and tackle other environmental problems associated with travel by car by reducing road traffic growth).

\section{Background}

Spetses is the only Greek settlement which has a complete ban of traffic. Prohibiting cars is not an arbitrary policy, nor an exception in a world that considers driving to be the foundation for the operation of the city. It is absolutely in line with the shift toward solutions closer to the community, to the environment, to the conservation of resources and the preservation of the natural landscape. On the island of Spetses, in the absence of cars, the inhabitants and tourists, without exception, have resorted to motorcycles. While the users of motorcycles are safe on roads without cars, that does not apply to pedestrians, particularly under conditions of the almost total absence of sidewalks. The extended use of motorcycles causes pollution, noise pollution and degradation of the landscape in the settlement. The movement of motor vehicles on the roads of the settlement is very difficult and highly dangerous due to their topography and due to the number of motorcycles during the summer months. The unlimited use of motorcycles is due to easy accessibility.

\section{Sustainability at destination level}

Much of the current tourism research has focused on investigating ways of making energy intensive transport systems more environmentally sensitive, or how to lessen impacts stemming from increased tourist traffic. Cullinane and Stokes [12] examine ways to minimise the impact of the car in environmentally sensitive areas, which have recreational or tourism appeal. The European project "CUSTODES" specifically relates the sustainable touristic development with 
sustainable mobility and accessibility: "sustainable mobility stands at the basis of more sustainable tourism, the tourist movement should transfer towards more sustainable modes of transport, and accessibility planning has become a statutory requirement of local authorities". Although widely used, the concept of accessibility is hard to fully define. Gould [13] referred to accessibility as a slippery notion, a common concept that everyone uses until faced with the problem of defining it and above all measuring it. Two widely accepted definitions demonstrate its richness. According to Bhat et al. [14]: 'accessibility is a measure of the ease of an individual to pursue an activity of a desired type, at a desired location, by a desired mode, and at a desired time'. Geurs and Van Eck [15] define 'accessibility as the extent to which the land use-transport system enables (groups of) individuals or goods to reach activities or destinations by means of a (combination of) transport mode(s). Accessibility does not simply relate to the qualities of the transport system (e.g. travel speed or costs), but also to the qualities of the land use system (e.g. densities and mix of opportunities). Accessibility becomes both a feature of the spatial system and the traffic and transport. Medlik [16] connects the term of accessibility with tourism: "in tourism, accessibility is a function of distance from centers of population, which constitute tourist markets and of external transport, which enables a destination to be reached. It is measured in terms of the distance traveled, the time taken or the cost involved".

Accessibility is the tool to facilitate people who live and move in areas where it is desirable to give priority to public transport, walking and cycling. After research, three types of areas of controlled accessibility can be defined: 1. cities, towns, villages, islands and territories which belong in this category, do not allow the free passage of motor vehicles, except in an emergency. Usually, these towns have been developed before the advent of cars, such as Venice and they retain their character today. The islands have an additional advantage as they are surrounded by sea, which is itself a factor of isolation, but it is also due to their limited size and thus the lack of available space to create an extensive road network; 2. A second category includes cities or large areas in them, which are areas in which the traffic is regulated in order to reduce the problems which occur from extensive car use. Walking, cycling and more environmentally friendly forms of travel, are prioritized here, but there are a few cases where they have to co-exist and share the space with cars; 3 . The areas that fall into this category are the areas of controlled accessibility. These are in fact pedestrianized areas corresponding to the older parts of cities around which the newer parts of the town have been developed later or even to individual shopping streets. Priority is given to cyclists and pedestrians, to the creation of shared public space and to the aesthetic enhancement of the landscape.

A large number of islands and resorts are located in the lists of cities of controlled traffic. The islands are cut off from the mainland and can easily keep cars away. Measures are required in order to regulate freight transport, emergency vehicles, etc., especially in the case of large islands with scattered villages and settlements. The tourist resorts, mainly for economic reasons, are developed as areas of controlled motorized traffic because it is understood that 
the use of motorized vehicles reduces the profits of traders and shopkeepers, as they are seen as less attractive destinations for visitors. Alayo [17] points out that the growing increase in motor vehicle use is burdening cities with increasing problems and costs related to congestion, accidents, loss of amenity and space, noise, poor quality of life, poor accessibility, pollution, poor urban air quality and energy consumption, which have adverse effects on both the natural and built environment. Public transportation, bicycles, walking or electric vehicles are the main solutions in such cases, and even boats, fishing boats and ships can serve the coastal settlements. 'Green' transport is often an important consideration in the amelioration of urban transport problems. However, as Whitelegg [18] highlights: "vehicles with zero emissions, zero fuel consumption and virtually zero impact on pedestrians, cyclists and urban population densities might be 'green' but then we might as well have rediscovered the bicycle or feet".

Tourists wish to rest and get to know the place and its history. The presence of the car is a barrier that prevents the realization of their desires. It is a synonym to noise, pollution, and accidents and to the distortion of urban and architectural aesthetics and physiognomy. The argument that comes with the car is that it serves the transportation needs of tourists. However, in small places where distances are limited, there are many alternative mobility solutions, such as cycling, walking or electric bikes. Walking allows tourists and residents to discover the streets of the village through an enjoyable physical activity. It is accessible to all and the aesthetic parameter of space, the quality of life, the quality of air, peace, health, safety and the social environment can be enjoyed. By bicycle, transport is converted into an opportunity for enjoyment and getting better acquainted with the place in which you live or visit. The first priority for visitors is not a fast means of transport but to stop in public places that are really attractive due to their character. The main desire of the visitor is not speed but the joy of moving around.

\section{Methodology application and results}

The starting point of the research was the investigation of the European experience on issues regarding the areas of controlled accessibility. Three main categories of areas of controlled accessibility were identified as mentioned above. Their relation to tourism was analyzed through the urban and transport framework of each city, focusing on the planning principles, the technical characteristics in relation to accessibility and the promotion of tourism. The results formed a useful reference point for the future steps of research, especially for important decisions such as the shape of the network, and the basic design principles. In the next phase, a methodology leading to a proposal for a clear, functional and safe network and a pleasant environment was developed. The aim was to involve the citizens in the decision making process concerning the future of their city, in order to avoid a top-down approach. Specifically, the methodology comprises four successive steps: 
1. Identification of urban and social characteristics.

2. Identification of problems.

3. Development of scenarios.

4. Participatory evaluation/choice of scenarios.

\subsection{Identification of urban and social characteristics}

Land use: Land use has a significant impact on transport. The hotels and the "rooms-to-let" are of particular interest for tourists. Other places of interest which are usually visited on a daily basis are the shopping and entertainment areas. Archaeological places and museums are not visited on a daily basis, but are of great importance. The most crowded area is close to the port due to the high concentration of land use that attracts a lot of people. The spatial distribution of land use is shown in Figure 1.

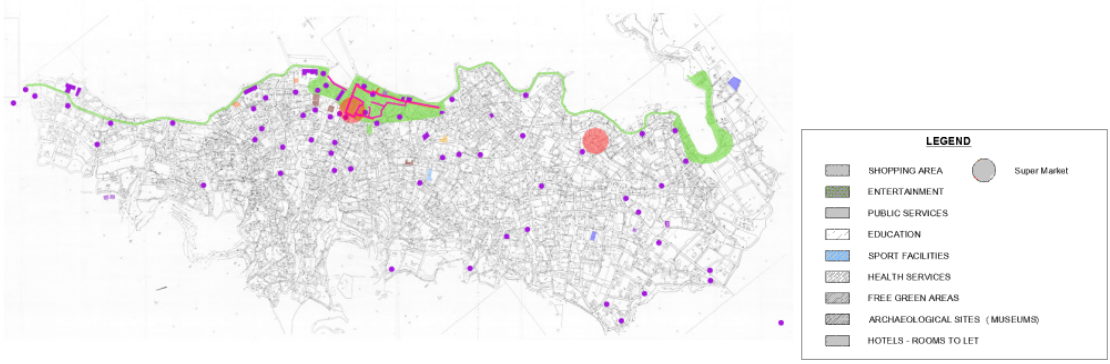

Source: Own elaboration

Figure 1: The spatial coverage of land use.

Built environment: The town of Spetses has been identified by the Ministry as a traditional settlement, which has maintained intact the image it had in the past, and the local characteristics. The buildings have a common architectural style, the maximum number of floors is two, and the maximum height of the building is up to 7 meters. Inside the village, artisanal and industrial units are not allowed, apart from small family businesses, laboratories and shops. According to the census of 2001, 3,880 permanent and holiday houses were registered.

Geometry of the network: The roads are made for walking and perhaps for transporting animals. They are complex and unsuitable for cars. The geometry of the network is irregular, the width of the road is constantly changing (Figure 2), straights roads are rare and there are many deadlocks. Few roads continue through a large part of the city. Travelling in the city is characterized by continuous curves and low speeds. 


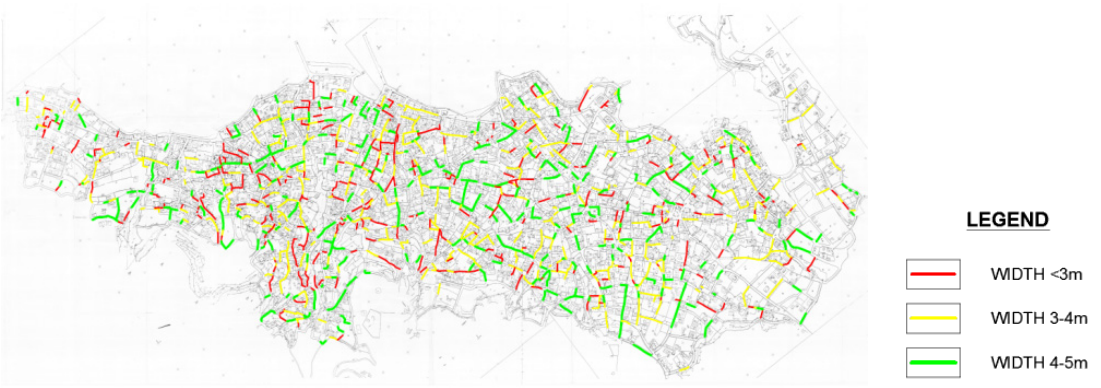

Source: Own elaboration

Figure 2: Roads according to their width.

Visibility in nodes/intersection: A node is defined as the intersection of a route with a road of equal or higher hierarchical level. Most of the nodes/intersections of the settlement are considered dangerous even when moving at $30 \mathrm{~km} / \mathrm{h}$ (red intersections in Figure 3 ). A visibility study was applied in all the intersections of the settlement.

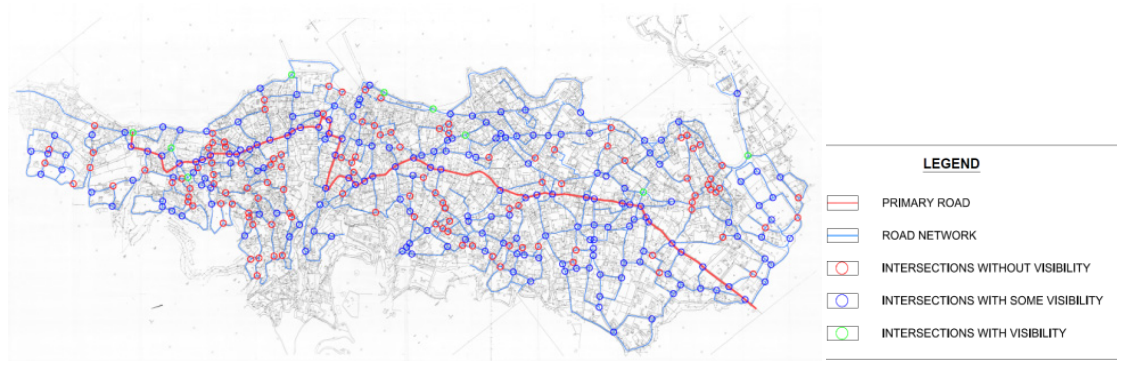

Source: Own elaboration

Figure 3: Classification of nodes according to their visibility.

Transportation and restrictions: Spetses is an island that belongs to the second category of areas with controlled accessibility, areas that do not allow the free movement of cars and trucks for the most part. For this reason they have adopted restrictive measures for traffic, which aim to ensure the convenience of the residents and visitors of the island, while protecting the natural environment and ensuring the enhancement of quality of life. Residents' cars may be parked but they are not authorized to travel around the island. The only vehicles that are allowed to move are emergency vehicles and ten cabs. The use of motorcycles is allowed almost everywhere across the island. There are some restrictions which vary depending on the season, in order to avoid the routes with a high concentration of people. 
Commuting and traveling on the island: It was observed that a large part of the population uses motorcycles even for the shortest trips $(<500 \mathrm{~m})$. Motorcycle users are all ages, but it should be noted that people over 65 years avoid motorcycle use. The phenomenon of the extensive use of motorcycles intensifies during the summer months because of the tourists. During the summer months when it is restricted to cross the coastal zone of the city for several hours, the roads in the settlement are filled with motorcycles. Something to be highlighted is the bad condition of most of the motorcycles as they are old and badly maintained.

\subsection{Problems}

Trying to overcome the difficulties faced by the movement of cars on the extremely difficult roads of the settlement, and by the ban of car traffic, residents have resorted to motorcycles. They are flexible in the narrow streets, easy to use, can be parked anywhere, are easy to get on and off, they stop and start without delay, have minimal fuel consumption and are affordable to buy. In the cases of other Greek cities the main deterring reason for using a motorcycle is the security problems due to the presence of cars. In Spetses, this problem does not exist. At the same time, due to the continuous curves of the roads, high speeds are not possible and this gives confidence to women and older people, who are more sensitive to matters of safety. While motorcycle users are safe, pedestrians are not, especially in roads with an almost total absence of sidewalks. There are also serious problems of visibility at intersections which increase due to the absence of sidewalks. Motorcycles travel very close to buildings, resulting in dangerous "meetings" with the pedestrians. This danger also applies to motorcycles traveling from different directions.

Does the motorcycle smoothly integrate on the streets of the village?

The answer is clearly negative because it is a vehicle that pollutes and makes a lot of noise. In conditions of large roads with more regular geometry, pollution and noise from motorcycles is suppressed for two reasons:

- the large width, the ventilation of roads and the turbulent flow of air facilitate the diffusion of pollution and noise;

- noise and pollution from cars create conditions where additional pollution from motorcycles becomes less noticeable.

In the case of the village of Spetses, where due to high temperatures house windows stay open almost all day long, pollution and noise is perceived by the tourists as an undesired degradation of a traditional settlement. The inclination of the roads in combination with the inadequate maintenance of the motorcycles aggravates emissions and noise. The road network which is unsuitable for car use in combination with the ban of car traffic creates a serious side effect. Cars were replaced by motorcycles and the environmental impact for those inside their homes is very serious, especially during the afternoon and night hours, and for pedestrians. The problem of safety for pedestrians and particularly for the elderly and children in the streets, which would normally be meeting places for conversation and entertainment, is also severe. 


\subsection{Development of scenarios}

The issue therefore of the presence or exclusion of motorcycles does not arise as a technical issue. There is no transport model that could prove or reject the need for a road or an area to be pedestrianised. Such a decision depends on the priorities and values of the society in each place. It depends on general cultural issues that determine the decisions about what would be tomorrow's form of the city. The technique can make any decision functional. However, not all solutions are applicable, and their effects are not the same. They depend largely on geometric characteristics and the capacity of each road especially in historical settlements which were developed before the invention of the car. Assuming Spetses decided to allow cars to move freely in the settlement, their effects on the settlement and the economy would be dramatic. The mainstay in all scenarios was to enhance safety and to improve quality of life.

The criteria for the development of the scenarios were selected by the research team in collaboration with the representatives of the municipality.

Use of motorized and non-motorized means of transport: This describes the level of safety of a route. It was calculated as the quotient of the number of routes suitable for motorized and non-motorized means of transport.

Junction safety: This describes the level of safety of each intersection. It is calculated by the visibility study performed for the speed of $50 \mathrm{~km}$ and $30 \mathrm{~km}$.

Natural environment: This describes the degree of presence of natural elements (e.g. stream, coastline, forest, urban park) along the route.

Built environment: This describes the quality of urban-architectural environment along a route.

Accessibility to the main uses: This criterion regards the number and type of urban activities that are accessible from a route. Accessibility is defined as the amount of services and jobs that people can access within a certain travel time, considering multimodal modes of transport such as walking, biking, driving and public transport. The examination concerned how many of them fall into a buffer zone of $250 \mathrm{~m}$ from the route.

Two scenarios were proposed, which have as their backbone the restriction on the movement of motorcycles. The objective of both scenarios was to optimize the movement of residents and tourists. New traffic arrangements are proposed which are oriented to the safety of pedestrians, to the promotion of cycling and walking and to the aesthetic and cultural promotion of the settlement.

\subsection{Final selection}

Through 2 community meetings the final scenario was selected. By bringing together a cross-section of viewpoints, a community meeting was the perfect setting to exchange ideas and information about the future of the island. In the meetings all the elected municipal counsellors, residents, representatives of the shop owners, hotel owners and taxi drivers were present. First, the research team presented the criteria and also presented the different scenarios which were the results of different weighting of the criteria. A discussion followed the presentation, where opinions were shared. 
The scenario selected included the creation of two parking areas for cars, on the outskirts of the settlement in order to minimize the existence of cars in the settlement. A route towards the parking areas was specified based on the route with safer junctions and a minimum impact on the environment of the settlement.

There would be a gradually reduction of the number of cars entering the island.

There would be a re-organization of the road network in order to exploit the potentials of its geometry in favour of the residential areas and the areas of particular interest.

Ring routes are adopted in order for safer access to the central areas and to points of interest, as seen in Figure 4, where the reorganisation of the roads is pictured. Additionally, in order to protect the desired areas, small scale interventions for the road environment were proposed. Some impasses (similar to a "cul-de-sac") were created in order to reduce high speeds and the movement of motorcycles through residential areas. Traffic at the network level is optimized as the local roads are transformed into one way streets. This helps to ensure safer intersections for pedestrians, cyclists and users of motorcycles and in minimizing frontal collisions. It also contributes to organizing the space at road level by specifying a "traffic corridor" and utilizes the space on either side for planting. The rings routes remain two way roads as an alternative route cannot be provided due to the irregularity of the road network.

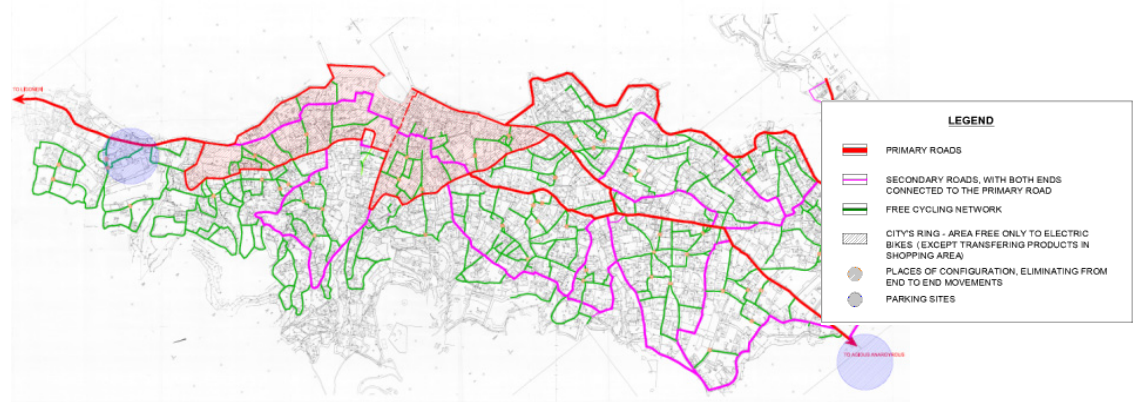

Source: Own elaboration

Figure 4: Reorganisation of the roads.

\section{Conclusions}

In Greece, that is hamstrung of the car, Spetses is the only Greek settlement which has imposed a total ban of cars. Nevertheless, the mobility options of its residents endanger the form of the settlement, its environment and its source of revenue. This study was an attempt to realize the desired form of the future settlement for residents and tourists. 


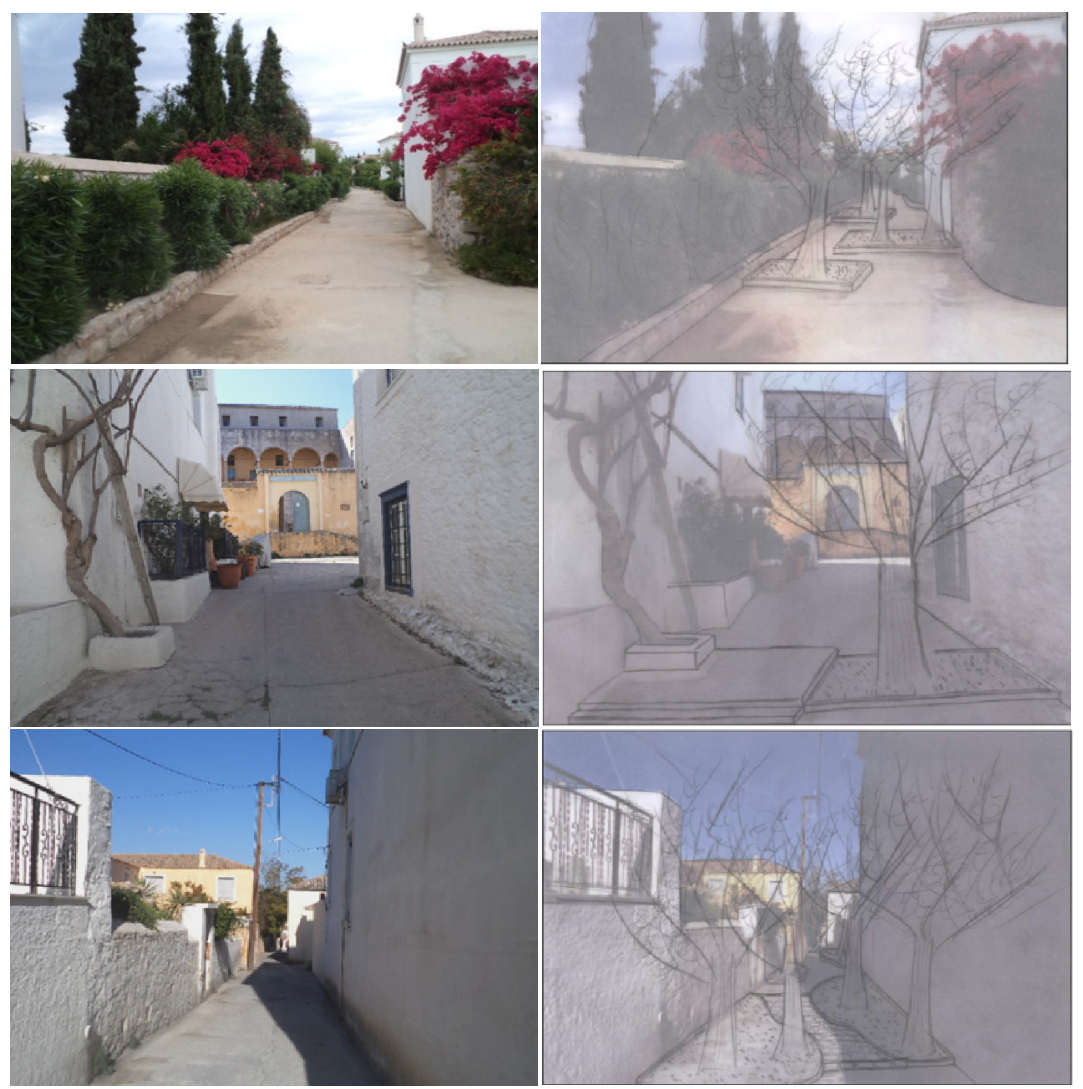

Source: Own elaboration

Figure 5: Design of obstacles for motorcycles.

The main contributions of this paper are three-fold. First, the process of planning aimed at offering public spaces to residents, which are safe, open and quiet. In their everyday life the quality of public spaces affects their lives and the measures proposed had as their objective the enhancement of the feeling of safety and comfort and to make them meeting points, reinforcing the social life of the settlement. There is also a strong tourist dimension in the selection of measures proposed. The purpose of planning is to make the place attractive and enjoyable for tourists. This happens when they come into contact with the place and its people, when they enjoy the details of the settlement and read its story through its roads and buildings. The objective was to rearrange space in order for the tourists to feel calm and welcome on the island, to enjoy the place and to invite them to stay and revisit it. 
In addition, the preservation of the natural and built environment has succeeded through the scenario selected. Air and noise pollution will be limited and the image of the settlement will improve. The methodology is useful for all the tourist areas which are in danger due to the excessive use of motorized means of transport.

Finally, it is worth highlighting the importance of the effective participation of citizens in planning for sustainable mobility in cities. The involvement of the public in the final decision of the scenario aimed at familiarizing them with the possible solutions and gaining their acceptance as they are the ones who would be affected the most from the planning.

\section{References}

[1] Wilkinson, D., 1997. Towards sustainability in the European Union? Steps within the European commission towards integrating the environment into other European Union policy sectors, Environmental Politics, 6(1), pp. 153-173.

[2] Lane, B., 1994, Sustainable Rural Tourism strategies: A Tool for Development and Conservation, Journal of Sustainable Tourism 2, pp. 102-111.

[3] Hunter, C., 1997, Sustainable tourism as an adaptive paradigm, Annals of Tourism Research, 24(4), pp. 850-867.

[4] Butler, R., 1999. Sustainable Tourism: A State-of-the-Art Review, Tourism Geographies, 1, pp. 7-25.

[5] Burns, P., 1999. Paradoxes in Planning: Tourism Elitism or Brutalism? Annals of Tourism Research, 26, pp. 329-348.

[6] Inskeep, E., 1991, Tourism Planning: An Integrated and Sustainable Development Approach.

[7] Leiper, N., 1990, Tourist attraction systems, Annals of Tourism Research, 17(3), pp. 367-384.

[8] Lumsdon, L., Page, S. J. 2004, Progress in transport and tourism research: reformulating the transport-tourism interface and future research agendas, Tourism and transport: issues and agenda for the new millennium, pp. 1-27.

[9] Page, S., 2005, Transport and tourism: global perspectives, Pearson Education.

[10] Schlich, R. et al., 2004, Structures of Leisure Travel: Temporal and Spatial Variability, Transport Reviews: A Transnational Transdisciplinary Journal, 24(2), pp. 219-237.

[11] Dickinson, J., Robbins, D., 2006. Using the car in a fragile rural tourist destination: a social representations perspective.

[12] Cullinane, S, Stokes, G, 1998, Rural Transport Policy, Elsevier.

[13] Gould, P. 1969. Spatial Diffusion, Resource Paper no. 4. Commission on College Geography, Association of American Geographers, Washington, DC. 
[14] Bhat, C., S. Handy, K. Kockelman, H. Mahmassani, Q. Chen, L. Weston. 2000. Development of an urban accessibility index: Literature review. Research project conducted for the Texas department of transportation. University of Texas, Austin, TX: Center for Transportation Research.

[15] Geurs, K.T., J.R. Van Eck. 2001. Accessibility measures: Review and applications. Rijksinstituut voor Volksgezondheid en Milieu (National Institute of Public Health and the Environment, RIVM) and Urban Research Centre. Bilthoven/Utrecht, Netherlands: Utrecht University.

[16] Medlik, S., 2003, Dictionary of travel: tourism and hospitality, Butterworth-Heinemann, pp. 273.

[17] Alayo, J.A., 1998, The Walking City: An obsolete design or the city of tomorrow, PTRC Education and Research Services Limited, pp. 269-78.

[18] Whitelegg, J., 1993, Transport for a sustainable future: The case for Europe, Belhaven Press (London and New York).

[19] Department for Transport, 2005. Focus on Personal Travel, 2005 Edition. London: The Stationary Office. 